Sumozas García-Pardo, Rafael.

Universidad de Castilla-La Mancha.

\title{
Imágenes fotográficas para la investigación y docencia en Artes Visuales.
}

\author{
Photographic images for research and teaching in Visual \\ Arts.
}

TIPO DE TRABAJO:

Comunicación.

PALABRAS CLAVE:

Fotografía Digital; Educación; Artes Visuales.

KEY WORDS:

Digital photography; Education; Visual arts.

RESUMEN.

Las fotografías digitales constituyen para el profesor de educación artística un buen recurso para el desarrollo de su docencia, el manejo que hace de imágenes fotográficas encierra una serie de potencialidades que comunican y transmiten ideas sobre la cultura visual en la que estamos inmersos. Las fotografías y su realización están al servicio de las distintas metodologías de investigación desarrolladas en educación. Las imágenes fotografías potencian y generar estructuras transversales de conocimiento en la educación en general y para la educación artística en particular, ya que éstas, utilizadas como motivo y recurso permiten comparar diferentes conceptos y perspectivas, además pueden revelar su potencial en el desarrollo de las Artes Visuales, en la medida que tienen una inevitable necesidad de generar conocimiento transformador a través de la investigación realizada con las propias imágenes. Este estudio se evalúa el desarrollo de las Artes Visuales por parte del profesor de educación artística mediante la realización y manipulación de fotografías digitales y parte de un proyecto de cooperación desarrollado entre la Universidad de Castilla-La Mancha (UCLM) y la Universidad Nacional Autónoma de México (UNAM), con el objetivo acercar la Cultura Visual y las Nuevas Tecnologías desde un programa pionero en la educación estética y artística como es el Taller Infantil de Artes Plásticas en la Facultad de Artes y Diseño de la UNAM coordinado por la Mtra. Evencia Madrid y que contribuye al desarrollo integral de jóvenes de diversos sectores sociales y económicos en México.

\section{ABSTRACT.}

The digital photographs constitute for the teacher of artistic education a good resource for the development of his teaching, his handling of photographic images includes a series of potentialities that communicate and transmit ideas about the visual culture in which we are immersed. The photographs and their realization are at the service of the different methodologies of investigation developed in education. The photographic images promote and generate transversal structures of knowledge in education in general and for artistic education in particular, since these, used as a motive and resource allow to compare different concepts and perspectives, and may reveal their potential in the development of the Arts Visual, to the extent that they have an inevitable need to generate transformative knowledge through research done with the images themselves. This study evaluates the development of Visual Arts by the art education teacher through the creation and manipulation of digital photographs and part of a cooperation project developed between the University of Castilla-La Mancha (UCLM) and the National Autonomous University of Mexico 
(UNAM), with the objective of bringing Visual Culture and New Technologies closer to a pioneering program in aesthetic and artistic education, such as the Children's Workshop of Plastic Arts at the Faculty of Arts and Design of UNAM, coordinated by Mtra. Evencia Madrid and that contributes to the integral development of young people of diverse social and economic sectors in Mexico.

\section{CONTENIDO.}

\section{Fotográficas para la investigación y docencia en Artes Visuales}

En la Universidad Nacional Autónoma de México (UNAM) se ha enseñado Arte en México por más de dos siglos y desde el 21 de marzo de 2014 la Escuela Nacional de Artes Pláticas (ENAP) se transformó en Facultad de Artes y Diseño (FAD), institución que tiene diferentes planteles para la enseña del Arte, Xochimilco, Ciudad Universitaria (CU), Taxco y el más antiguo, la propia Académica de San Carlos de México, fundada el 4 de noviembre de 1781 y que desde el siglo XVIII y durante XIX ya era el referente mexicano para la enseña del Arte y germen del importante movimiento de muralistas que rompieron con la enseñanza formal y abrió las puertas de la modernidad de la educación artística en el siglo XX hasta que en 1910 se integró en la entonces Universidad Nacional de México (Báez, 2009). Ya en 1929 consiguió su Autonomía como UNAM y se creó en 1933 la ENAP en el edificio histórico de Academia de San Carlos, hasta que en 1979 se trasladó a la delegación de Xochimilco, al sur de la Ciudad de México. En las nuevas instalaciones se reorganizaron los estudios de Artes Visuales, se sintió la necesidad de profundizar en la enseñanza del arte para los más jóvenes y momento en el que fundó en 1983 el Taller Infantil de Artes Plásticas (TIAP) dirigido a niños de entre 5 y 12 años, el cual lleva en funcionamiento cerca de 34 años y ha contribuido a la educación artística de un gran número de futuros espectadores de arte en la República Mexicana, entre los cuales se fomentó el gusto estético al igual que su imaginación, creatividad y estima por el entorno y el medio social. En el TIAP, a los alumnos de diferentes licenciaturas de las FAD se les permite una experiencia en el desarrollo infantil e iniciar su labor docente no formal para trabajar con niños como asesores, con ello se contribuye en el desarrollo integral del niño estableciendo un vínculo con la enseñanza de las Artes Visuales, además de propiciar su autoestima.

La fundadora del TIAP, Evencia Madrid Montes es una de las educadoras artísticas de más larga tradición en Latinoamérica, estudió en la Academia de San Carlos de la UNAM donde realizó una Maestría en Artes Visuales y desde 1976 es profesora de Dibujo de la FAD y ha participado en un gran número de exposiciones plásticas dentro y fuera de México. En 1983 fundó el TIAP en la entonces Escuela Nacional de Artes Plásticas de la UNAM en Xochimilco, hoy FAD. Programa pionero para educación artística creado para favorecer el desarrollo integral de niños de diversos sectores económicos, incluidos los denominados "niños de la calle", siendo una activista social durante más de 30 años, atendiendo a más de cinco mil niños y realizando más de cien exposiciones internacionales dentro y fuera de México, lo que hizo que el TIAP se considerara como el mejor Servicio Social de la UNAM y sus egresados sean educadores artísticos destacados, cuando aún no se hablaba de educación artística sino más bien de pedagogía, enseñanza o aprendizaje del arte o de las artes en México y estaban llegando las corrientes que promovían la educación en Artes Visuales fuera de la escuela y en contacto con los diferentes niveles sociales y económicos.

Evencia, impartió innumerables cursos de educación artística para niños en diferentes instituciones públicas y privadas, entre las que destacan fundaciones para niños de la calle, como las comunidades de Villa Estrella, Hogares Providencia, Casa Alianza, Casa Ollin, Casa Satán Hipólita, Renovación Unión de Fuerza Unión de Esfuerzos, con internos del Reclusorio Sur, en Delegaciones, casas de cultura, institutos culturales y un sinfín de entidades en las que formó a promotores culturales, maestros y niños en diversos estados de la República Mexicana. Gracias a su destacada trayectoria en la educación artística infantil hizo que fuera invitada en numerosas ocasiones como jurado de arte infantil en diversas instituciones, entre las que destacan el Concurso Caroline Award o la Institución Chistel House, que atiende a niños en situación de abandono y marginación, o el Concurso Arte Bello de la Fundación Santa Hipólita que atiende a niños institucionalizados en asilos. El Concurso Ecológico de la SEP, en diversos estados mexicanos, el Concurso Nacional de Pintura Infantil Pfizer, el Concurso "Adiós a las Trampas" y "Un metro con alas" del Consejo Nacional para la Cultura y las Artes de México (CONACULTA), órgano desconcentrado de la Secretaria de Educación Pública creado en 1988, con el objetivo de promover y apoyar el patrocinio de eventos que propicien el arte y la cultura de la República Mexicana. El Concurso Nacional de Dibujo Infantil Lincosa, el Concurso “Amor, Paz y Seguridad” de la Secretaría de Seguridad Publica de México D.F., entre otros.

Recibió el premio y homenaje "Cautlicue" 2004, otorgado por la Coordinación Internacional de Mujeres en el Arte ComuArte, colectivo que surgió en México en 1994 con el propósito de dar a conocer la obra artística de las mujeres a través de la realización anual de encuentros internacionales que se celebran en el mes de marzo, en el marco de actividades del Día Internacional de la Mujer y el Día de la No violencia hacia las mujeres y las niñas, foro más importante de mujeres en el arte de Latinoamérica. En 2011 le fue otorgado a Evencia el Reconocimiento y la medalla Sor Juana Inés de la Cruz, distinción académica de la UNAM.

En el TIAP Evencia, ha buscado desarrollar la creatividad gráfica de los niños, mediante el uso de las artes como principal herramienta para generar estrategias para su desarrollo y que a su vez posibilitaran su inclusión social y educativa. La creatividad fue entendida 
como un factor importante a desarrollar en el taller, ya que posibilitó el entendimiento y comprensión del medio para posteriormente, realizar las propias adaptaciones y aportaciones, y con ello dar solución a las problemáticas o situaciones que día a día de manera cotidiana se presentaban. De acuerdo con (Torre, 1997) se entiende por creatividad, el potencial humano, capacidad de responder a situaciones o estímulos imprevisto, virtud personal que voluntariamente podemos dirigir, "transacción" entre la persona y el medio. Esta característica por ende no es exclusiva de unos cuantos, sino que es propia de los seres humanos, y su desarrollo depende en gran medida de las estrategias empleadas para potencializarla. Se considera que uno de los principales factores que contribuyen a su desarrollo son los ambientales o contextuales a partir de las experiencias que se generan por las instituciones sociales en las que el sujeto se encuentra inmerso (Alfuhaigi, 2015). La inclusión de la creatividad en la educación artística inicial del niño favorece su desarrollo integral y ayuda a la adquisición de otras habilidades cognitiva, debiera ser una herramienta indispensable en todo tipo de educación.

EI TIAP se desarrolla como un elemento para potenciar la capacidad creativa a través de múltiples actividades y estrategias planteadas en éste y centra su aplicación en Ciudad de México y su área de influencia, para su implementación cuenta con los recursos y el apoyo de la FAD y para su desarrollo se tiene en consideración diversas investigaciones referentes a la creatividad. Según (Villegas, 2008) "la persona creadora, se nutre del medio, toma información de éste", si bien la actividad creativa es un potencial humano inherente, y que por ende todos poseen, resulta, de igual manera evidente, la parte subjetiva que involucra este proceso, dado que es la misma persona quien efectúa los cambios, modificaciones y transformaciones, depende de su intelecto, de sus experiencias y de su formación, la forma particular en la que habrá de desarrollar dicha actividad. En el TIAP, se tienen en consideración las necesidades del desarrollo del potencial creativo, para coadyuvar a un adecuado desarrollo integral del niño. Tal como afirma (Read, 1982) la principal misión en el campo de la educación del arte es facilitar el desarrollo creativo del niño, por lo cual el arte es una forma de explotar su "manantial" creativo.

\section{2.}

\section{Investigación, Artes Visuales y Educación en México.}

En el contexto mexicano debemos tener en consideración artistas como Diego Rivera, Alfonso Reyes, Roberto Montenegro o Manuel Rodriguez Lozano, entre otros, que se interesaron por el estudio y rescate de las tradiciones, las artes populares, las costumbres del pueblo y las pinturas infantiles, como demostración de la inquietud creativa del mexicano en general. Desde hace cerca de cien años ha habido interés por la educación artística en México, entre 1921 y 1924 se creó la Secretaría de Educación Publica y dentro de ella el Departamento de Educación Artística a cargo del pintor Adolfo Best Maugard, el cual creó un Método de dibujo denominado Método de Dibujo de Best Maugard que fue un verdadero manual de dibujo con fundamentos teóricos, su teoría fundamental era que con base a siete líneas primarias se podía construir cualquier forma de la naturaleza (Fernández, 1965). Estas líneas primarias tenían como parámetros la recta, pasaban por el círculo y concluían en la espiral, su método inspirado en el estudio de las culturas prehispánicas se impartió en las escuelas de la República Mexicana, publicado en forma de manual, hasta que el pintor Manuel Rodriguez Lozano modificó el método Best 1924 y en 1925 es suprimido definitivamente (Fernández, 2001).

En México, la (SEP) la responsable de la organización del sistema educativo y la Secretaria de Educación es quien supervisa los lineamientos planteados tanto en el sector público como el sector privado así como todos los niveles educativos (inicial, básico, medio-superior y superior). En educación primaria se tiene la asignatura educación artística, que contempla el estudio de una forma conjunta la danza, el teatro, la música y las Artes Visuales.

El desarrollo de la capacidad creativa no debiera limitarse únicamente a un área, sino que por el contrario debiera formar parte del marco curricular oficial de las instituciones educativas, para que con ello los alumnos puedan estar preparados y cuenten con las competencias básicas requeridas para afrontar las demandas y situaciones que la sociedad actual requiere. Desde la Secretaría de Educación Pública se intentó dar respuesta a una serie de interrogantes relativos a la enseñanza del Arte y la didáctica de las Artes Plásticas (SEP, 2006) en los diferentes programas de estudio, para ello se dio mayor peso a la educación artística consiguiendo unificar programas curriculares e invitando al profesorado a explorar las artes en un sentido amplio, a partir de sus rasgos característicos, para que los estudiantes se expresen artísticamente en todos los niveles educativos (inicial, básico, medio-superior y superior) en un contexto de "crisis" del arte contemporáneo (Gaillot, 2013).

Con base en los planteamientos de la Secretaría de Educación Pública de México a través de la Subsecretaría de Educación Básica se constata que existen determinadas competencias a desarrollar al respecto, entre las cuales destacan las planteadas para el nivel primaria, como son la Percepción estética. Dicha competencia implica la integración de los datos e información percibida del entorno mediante los distintos sentidos, conlleva un proceso de análisis y reflexión acerca de éstas para proveerles de un significado y una propia valoración. La Abstracción interpretativa. Hace alusión al proceso metacognitivo y actividades de pensamiento superiores, mismo que posibilitan los procesos de escritura, descripción, comparación, contrastación, categorización entre otros. Se busca que al realizar estos procesos el alumno logre la congruencia entre su discurso y su acción. Por último la Comunicación creativa. Busca que se desarrollen estrategias y sistemas diversos de comunicación adicionales al verbal; tales como el gestual, el corporal, el semiótico, el musical y el visual (Hernández, et al., 2011). Estas competencias generan la motivación del alumno, despiertan su creatividad y 
promueven habilidades de investigación y su aprendizaje significativo en los alumnos, ya que se espera que desarrollen tres principios básicos: percepción, producción e investigación-reflexión.

Las artes ante todo representan una idea de equidad en cuanto la posibilidad de expresarse, dado que para ello no se requiere mayor conocimiento con respecto la manipulación de los materiales y técnicas. Las artes en ese sentido, buscan promover la idea de autoexpresión creativa. El arte es una forma inequívoca de rescatar la ciudadanía de las clases menos favorecidas económicamente. El ejemplo del TIAP entre otros lenguajes, fuera de la educación formal, facilita la inserción social de las clases menos favorecidas (Torre,1997)

Según Evencia Madrid el objetivo el TIAP es que los más jóvenes se acerquen al arte y que "el niño desde pequeño se familiarice con él y lo encuentre placentero, ya que es muy probable que el día de mañana sea un futuro espectador". El TIAP tuvo como antecedente los talleres para niños que impartían los alumnos de la Academia de San Carlos de México, hasta que en 1983 pasó su sede al Xochimilco, el Taller era una alternativa más para que los estudiantes de Artes Visuales realizaran su servicio social en talleres de modelado, origami, pintura, grabado, serigrafía y fotografía desde donde enseñan a los niños diferentes técnicos y ellos tienen la libertad de hacer la composición que deseen para no limitar su capacidad creativa. En este proceso es importante la realización de una exposición final con al finalidad de exhibir los trabajos que los niños realizan a lo largo del taller, en palabras de Evencia Madrid: "con la exposición se busca que los niños se sientan familiarizados con las galerías y los museos, para que en un futuro les sea agradable asistir a este tipo de espacios".

EI TIAP es un servicio social donde los alumnos de las diferentes licenciaturas de la FAD pueden iniciar su labor docente desde las Artes Visuales con alumnos de educación infantil y primaria, para ello previamente se imparten cursos de formación de asesores a través de los cuales se les dan a los alumnos universitarios los conocimientos necesarios para trabajar con niños, estos cursos son coordinados por la Mtra. Evencia Madrid e impartidos por maestros de la FAD que tienen experiencia en el desarrollo infantil.

Entre los objetivos del TIAP se encuentra cumplir con los fines de la UNAM en lo que se refiere a docencia, investigación y difusión cultural, así como incorporar a los alumnos de la FAD al proyecto de formación de personal docente, por medio de la experimentación como asesores (docentes) en el Taller Infantil de Artes Plásticas, por otra parte, se busca contribuir al desarrollo integral de los niños estableciendo un vínculo con la expresión plástica; Estimular y desarrollar en el niño su gusto estético, sus habilidades y sus capacidades artísticas. Estimular en el niño la imaginación y la creatividad. Propiciar y estimular en el niño la sociabilidad, así como la reafirmación de su autoestima, mediante la expresión plástica. Sensibilizar a los padres en la importancia que tiene la educación estética y artística en los niños como parte de su desarrollo integral.

\section{Investigación y fotográficas en el Taller Infantil de Artes Plásticas.}

Al mismo tiempo que se desarrollaba la alfabetización artística en el TIAP, se pudo realizar en colaboración con la Mtra. Evencia Madrid un taller de alfabetización digital con niños con edades comprendidas entre 5 y 12 años, el cual se llevó a cabo en el Plantel Taxco de la FAD de la UNAM con buenos resultados. Con el Taller se pretendió iniciar a los alumnos en el manejo y creación de ilustraciones y fotografías con él fin de iniciar su formación digital, con un primer acercamiento a cámaras y herramientas electrónicas que permitían el reconocimiento de imágenes, su manipulación, análisis y evaluación lo que contribuyó a la creación y comunicación de cada alumno del TIAP de contenidos artísticos implícitos en sus producciones plásticas. Con la alfabetización digital se favoreció la toma de conciencia sobre la alfabetización plástica y sobres sus propias producciones. La instrucción digital encierra tres niveles: Icompetencia digital; II-Utilización digital y III-Transformación digital, siendo apenas competentes digitales los sujetos que alcanzan los niveles II y III (Martín, 2008). En el nivel I se trata de aprender a utilizar herramientas digitales y la tecnología de la que disponemos; En el nivel II, se trata de la aplicación de la competencia digital para responder a necesidades personales y profesionales; El nivel III ocurre cuando el uso que es hecho permite la innovación y la creatividad y una percepción de las alteraciones que a nivel profesional ocurren fruto de ese mismo uso de la metodología de los procesos alternativos en la práctica fotográfica (Lynn, 2007).

Las niños actuales que han crecido en el mundo digital, no dividen los recursos y las herramientas que los rodean en digitales o no digitales (Lynn; Rodrigo; Rosales, 2010), tienen nuevas formas de ver. Esta dicotomía la hacen los adultos, especialmente los mayores, que vivieron toda un época pre-digital y las transformaciones que se comprobaron en la sociedad a partir de la utilización generalizada de ordenadores. Pero dada la generalización del mundo digital, no solo la dicotomía anterior se muestra ineficaz, como formas de alfabetismo previas a lo digital acabarán siendo integradas en él. La enseñanza formal vino a promover la alfabetización digital, de una forma menos rápida de lo que ha sucedido en otros contextos de la sociedad. Así, en determinados medios socioeconómicos más favorecidos, los niños contactan desde temprano con las herramientas digitales. Como indica (Erstand, 2008) la competencia digital es frecuentemente adquirida fuera de la escuela, porque los profesores utilizan poco los medios digitales en el contexto de su práctica docente. $\mathrm{O}$, cuando lo hacen, la utilización de los referidos medios acontece de una forma menos amplia de la conseguida por los alumnos en otros contextos. Todavía, el acceso a las herramientas digitales puede ser profundamente desigual en función del origen social y económico de los alumnos. Como destaca (Martín, 2008), vivimos en un mundo profundamente desigual, y el acceso al mundo digital lo único que hace es acentuar las desigualdades existentes en distintos niveles. Así, los profesores tienen que evaluar el uso que 
hacen de las tecnologías y herramientas digitales, teniendo en cuenta a los alumnos que enseñan. Y cabe también que las escuelas promuevan las transformaciones necesarias que conduzcan a una democratización de los nuevos medios de la era digital.

El objetivo de este estudio fue que un grupo de niños que trabajaban en el TIAP, con diferentes técnicas artísticas reflexionaran sobre como mediante las fotografías que ellos mismos realizaban de sus trabajos plásticos conseguían ser conscientes de sus debilidades, fortalezas, obstáculos y motivaciones, al tiempo que iban construyendo su visión sobre la importancia de las Artes Visuales, este estudio pretende no solo la identificación del potencial creativo en un grupo de niños mediante la fotografía, sino que de igual manera, permitía la identificación de estrategias y actividades que posibilitan el desarrollo de esta capacidad; sentaba las pautas para investigaciones posteriores que se enfoquen en el perfeccionamiento de dicho potencial. Con el uso de la cámara digital se pretendió que el alumnado que se inició en el lenguaje fotográfico fuera capaz de expresarse visualmente y de dar su propio punto de vista sobre la imagen (Sumozas y Lekue, 2016). La necesidad de crear estrategias que fomenten esta capacidad en niños que trabajan en el TIAP, dado que las oportunidades de acceder a programas culturales y artísticos no son frecuentes.

Con el uso de la cámara digital se pretendió que el alumnado se iniciara en el lenguaje fotográfico y consiguiera ser capaz de expresarse visualmente mediante dispositivos móviles y dieran su propio punto de vista sobre las producciones plásticas que ellos mismos realizan previamente, con lo que se busca que el alumnado se acerque a la fotografía de una forma interpretativa, pero sobre todo de una forma creativa. Se desarrolló con los alumnos del TIAP ejercicios fotográficos que permitieron generar diálogos fotográficos, mostrando casos de estudio y modelos educativos basados en la utilización de la cámara digital, que ellos mismos reproducían posteriormente y que les permitió poner en común las posibilidades que ofrece la utilización de la fotografía con propósitos educativos.

Las prácticas que ser realizaron con los alumnos del TIAP partían del concepto de sucesión de imágenes mediante el desarrollo visual de series con el uso de cámaras digitales, se buscó que estas imágenes fueran coherentes individualmente y en conjunto para que todas las series tuvieran sentido y unión, el argumento que debían fotografiar era el hecho de crear una obra plástica, su propia obra, desde la generación de la idea a nivel teórico hasta llegar a la realización de la obra, pasando por las diferentes fases hasta su realización, esto les obligó a pensar en un argumento para la serie que llamaron "realización de una obra plástica", en la partes a fotografiar, en los actores para su realización, y al mismo tiempo tener en consideración que lo que se pretendía era proyectar una idea sin utilizar la palabra. Otro ejercicio de producción creativa que se realizó fue el autorretrato fotográfico, en el que los alumnos tuvieron que autorretratarse a sí mismos o mediante objetos o materiales que utilizan en el taller que los representaban por medio de una imagen o conjunto de ellas, el autorretrato permitió el desarrollo de su mirada fotográfica.

\section{Conclusión.}

Con este taller se pretendió contrastar algunas potencialidades que la era digital ofrece y que pueden ser investigadas en el ámbito de la educación artística. De hecho, el uso de ilustraciones y fotografías digitales crea nuevas posibilidades para tomar consciencia de las Artes Visuales y su uso puede contribuir a entender la realidad que nos rodea, porque su utilización no se limitó a entender como se trabajan técnicas artísticas como pintura, modelado, grabado u origammi, además se buscó demostrar de una manera construccionista que el referido uso de la fotografía ayuda a los alumnos del TIAP a desarrollar su forma de entender las Artes Visuales y la influencia que estas tienen en su desarrollo como persona. Los saberes los alumnos adquieren mediante el uso de la cámara digital pueden constituir una plusvalía en su formación y ayudarles a pensar en otras formas de abordar las cuestiones estéticas, desarrollando así su alfabetismo visual para la lectura de ilustraciones e imágenes.

\section{FUENTES REFERENCIALES.}

Alfuhaigi, S. (2015). School environment and creativity development: a review of literature. Journal of educational and instructional studies in the world, 5(2), pp. 33-39.

Báez, E. (2009): Historia de la Escuela Nacional de Bellas Artes (Antigua Academia de San Carlos) 1781-1910: Espiral: México, p. 312.

Erstad, O. (2008). Trajectories of Remixing: Digital Literacies, Media Production, and

Schooling. In C. Lankshear \& M. Knobel (Eds.). Digital Literacies. Concepts, Policies and Practices (pp. 177-202). New York: Peter Lang Publishing, Inc.

Fernández, J. (2001): Arte moderno y contemporáneo de México. Tomo II: El arte del siglo XX. México. UNAM, p. 84. 
Fernández, J. (1965): "Método de dibujo, de Adolfo Best Maugard". En: Revista Anales del Instituto de Investigaciones Estéticas.

Volumen IX, número 34. UNAM, p.111.

Gaillot, B.A. (2013): Elementos de una didáctica-crítica. Espiral, p.256.

González, M.A. (2002) Análisis dela educación artística no formal en la universidad. UNED: Madrid.

Hernández, A., García, E., Rodríguez, J., Dabdoub, L., Roldán, M., Quiroz, M. Castillo, O., y Torres, R. Morales, S. (2001). Las artes y su enseñanza en la Educación Básica. Subsecretaría de Educación Básica y Secretaría de Educación Pública. Teoría y práctica curricular de la Educación Básica. Secretaria de Educación Pública, México.

Lynn, G. (2007): Fotografía: Manual de procesos alternativos (coord.) UNAM, México. p.160.

Lynn, G.; Rodrigo C. y Rosales, A. (2010): Fotografía digital: desarrollo y reflexiones, UNAM, México. p.63.

Martin, A. (2008). Digital Literacy and the "Digital Society". In C. Lankshear \& M. Knobel (Eds.). Digital Literacies. Concepts, Policies and Practices (pp. 151-176). New York: Peter Lang Publishing, Inc.

Perdomo, E. (2005). Metodología lúdico-creativa para la educación plástica de los escolares del segundo ciclo de educación primaria.

Read, H. (1982). Educación por el arte. Buenos Aires: Paidós.

Secretaría de Educación Pública (2011): Plan de estudios 2011. Educación Básica. México.

Secretaría de Educación Pública (2006): Arte. Artes Visuales. Educación Básica Secundaria. Programas de Estudio: México.

Sumozas, R. y Lekue, P. (2016): La fotografía digital en la formación del profesorado en: Rodríguez, M.A., Nieto, E y Sumozas, R. (2016). Las tecnología en Educación. Hacia la calidad educativa. Madrid, Editorial Síntesis.

Torre, S. de la (1997): Creatividad y formación. México: Trillas

Villegas, B.R. (2008). "Estrategias docente en el desarrollo de la creatividad escolar". En: Revista electrónica de Humanidades, Educación y Comunicación Social, Año 3, №.5. (pp.65-76). 